\title{
CONSUMPTION FUNCTION IN THE CONTEXT OF CULTURAL AFFINITY ZONES
}

\author{
Terézia Vančová1 ${ }^{1}$ Luboš Střelec ${ }^{1}$ \\ ${ }^{1}$ Department of Statistics and Operational Analysis, Faculty of Business and Economics, Mendel University
}

Link to this article: https://doi.org/10.11118/actaun202068040797

Received: 30. 3. 2020, Accepted: 29. 6. 2020

To cite this article: VANČOVÁ TERÉZIA, LUBOŠ STŘELEC. 2020. Consumption Function in the Context of Cultural Affinity Zones. Acta Universitatis Agriculturae et Silviculturae Mendelianae Brunensis, 68(4): 797-806.

\begin{abstract}
Consumers' purchasing behaviour is affected at the microeconomic level by personal, psychological, situational, social and cultural factors. Beside the political and economic factors, culture with its beliefs, values, attitudes and traditions plays a substantial role also at the macroeconomic level in affecting national aggregate consumption, despite the recent phenomenon of globalisation. There is an evidence of excess sensitivity in European countries, which confirms that income change is a good predictor of consumption change. Clusters of European countries constructed according to single consumption functions correspond to some extent to the cultural affinity zones. Reactions (marginal propensity to consume) vary among formed groups of European countries and average consumption response is the highest in wealthier Western, followed by Central Europe and is the lowest in the South Europe. The results of this paper suggest that a stabilization policy may be more effective in an individualistic, hedonistic, rather a decentralised culture.
\end{abstract}

Keywords: consumption expenditure, cultural dimensions, disposable income, excess sensitivity of consumption, panel data models

\section{INTRODUCTION}

The worldwide markets are nowadays more integrated than ever before. One of the aspects of globalisation is the convergence of national income and technology, which can lead to possible homogenisation of consumption behaviour. But are the single estimations of consumption function of European countries the same or do they differ? Do their aggregate consumptions follow Permanent Income-Life Cycle Hypothesis or are excessive sensitive to disposable income? These questions are crucial for evaluating the impact of macroeconomic stabilisers because the effectiveness of policy stimulus programs depends on the responses of consumption expenditures to predictable income changes. This paper sheds light on the potential differences in consumption function estimations of European countries and analyses if they reflect cultural diversity in the context of cultural affinity zones. Culture has been defined by Hofstede G., Hofstede G. J. and Minkov (2010) as the collective 'software to mind' of the people in an environment that is why culture dimensions can explain the possible similarities and differences in consumption behaviour.

Consumption function has been an area of intensive study throughout the economic history until now. The concept of consumption function was first introduced by Keynes' Absolute Income Hypothesis (1936) that suggests consumption is determined by disposable income which means higher marginal propensity to consume (mpc) out of current income. This assumption has then been discredited by approaching Friedman's Permanent Income Hypothesis (1957) and Franco Modigliani and Richard Brumberg's Life Cycle Hypothesis (1954).

The Permanent Income-Life Cycle model believes that people smooth their consumption expenditures 
according to their lifetime resources and current income have only a small impact on consumption spending. Hall (1978) has moved this concept further to Random-walk Hypothesis which has showed the independence of consumption change from expected changes in income.

The empirical analyses have shown that Permanent Income-Life Cycle Hypothesis does not accurately mirror consumption behaviour. Flavin (1981) has pointed to the excess sensitivity of consumption to disposable income and Deaton (1987) to the excess smoothness of consumption to disposable income. Consumption responds less to innovations in income and more to anticipated changes in income than would Permanent Income-Life Cycle Hypothesis (Random-walk Hypothesis) expect. The lagged disposable income has a predictable value on the current consumption. The presence of liquidity constraints or precautionary savings is considered to be a reason of excess sensitivity of consumption to current income (Kaplan and Violante, 2014; Kueng, 2018; Einian and Nili, 2020).

Consumption expenditures are certainly affected by many drivers. The essential determinant of household consumption is disposable income, followed by wealth, house price changes, interest rates, expectations, unemployment and many others.

From a macroeconomic perspective, aggregate consumption is also influenced by culture as a definite pattern of behaviour and attitude. Naturally, from a microeconomic point of view, consumption behaviour in the same culture differs because of personal individuality. The integrity of human society is determined by the culture just as individual identity is determined by personality.

Hofstede G., Hofstede G. J. and Minkov (2010) differentiate culture from universal, inherited human nature on the one hand and from specific personality on the other hand. There are many definitions of the term culture. Hofstede (2001) defines culture as the collective programming of the mind which distinguishes the members of one human group from another'. Kluckhohn (1951) points out that 'culture consists in patterned ways of thinking, feeling and reacting. The essential core of culture consists of traditional (historically derived and selected) ideas and especially their attached values'.

culture is a collective, shared and learned feature of a community with certain elements like symbols, heroes, rituals and values. Culture is manifested only by comparison.

States are not the same as nations and states and nations are not equal to societies. Hofstede G., Hofstede G. J. and Minkov (2010) point out to the wise usage of cultural differences in research. The concept of culture is more strongly tied to society as an historically developed system than to nation. Culture is not just about nationality, so there is not a single, agreed number of cultures that exist in the world. But there is still the possibility of recognizing a culture, of understanding cultural patterns and changes. Nationality as a simplified expression for society and therefore culture is employed because of clear access to all kinds of statistic data for nations.

The values and norms prevailing in the cultures of individual countries are the result of historical development and are formed by several different factors like organisations, art, politics, economics, religion etc. The division of the socio-cultural environment into individual parts, including detailed explanation and description, is necessary for a better understanding. This permits a better analysis and definition of the cultural differences of the various European nations and from this knowledge it is possible to deduce their impact on consumer behaviour and consumption expenditure.

One of the quantitative surveys of national culture is a study by Geert Hofstede first published in 1980. He used a double-pole scale to figure out the intercultural differences objectively and comprehensibly. He was inspired by Inkeles' and Levinson's (1969) basic tendencies in the behaviour of members of each culture and formed four dimensions of culture which could be measured relative to other cultures. Scores on these dimensions are listed for over one hundred countries.

Dedicated research led to the extension of the basic four-dimensional model to a six-dimensional model consisting of the following dimensions (Hofstede, Hofstede and Minkov, 2010):

- Power Distance (PDI): expresses how the less powerful deal with unequally distributed power and how the hierarchical order in society is tolerated.

- Uncertainty Avoidance (UAI): indicates how people handle uncertainty in the future.

- Individualism versus Collectivism (IDV): a high score represents an individualistic culture where the individual has a strong awareness of his independence and responsibility for himself. By contrast, in collective cultures the opinion and interest of the community prevails over individual opinion and interest and the major effort is to achieve consistency and consensus.

- Masculinity versus Femininity (MAS): in masculine society, achievement, power and lower tolerance are generally accepted. The ideal of feminine society is prosperity, modesty and politeness in relationships and welfare.

- Long Term versus Short Term Orientation (LTO): societies with low values of this index are shortterm oriented with respect to traditions, a tendency to live wasteful life and to be in debt. Longterm orientation implies adapting to changing circumstances and suggesting a saving behaviour and values like dedication and persistence.

- Indulgence versus Restraint (IVR): Indulgence symbolizes a free-minded society related to enjoying life in opposite to restraint society controlling its desires. 
Many studies applied to the explanation of cultural differences have used Hofstede's dimensional model of national culture. Although the country ranking originated in the 1970s, many reproductions and enhancements of Hofstede's study on diverse samples have confirmed that his country scores are still valid.

\section{Cultural Development of European Countries}

One of the most dominant cultures in the world is Western European culture, which currently plays the role of a civilizing hegemony. The Second World War divided Europe into political and economic blocks which led to divergent development in terms of politics, economy and culture.

Usunier and Lee (2013) segregated European countries into so-called cultural affinity zones and designed a map of these zones (Fig. 1). Cultural affinity zones represent similar aspects of language, religion, consumption patterns as well as work and family life relations (Usunier and Lee, 2013). Cultural affinity zones correspond to a large extent to national cultural groups but Usunier and Lee (2013) are aware of the assumption that cultures step over national borders. Scandinavia and the Mediterranean countries are quite separate, while the central European countries form an imaginary bridge between them.

Kale's study (1995) investigates the cultural associations of seventeen European countries aggregated on the basis of Hofstede's four initial cultural dimensions. He created three clusters similar to Usunier's groups.

Nevertheless, on the one side, economies of scale in production, innovations and technology lead to a global market and the convergence of consumers' needs and desires (Levitt, 1983). The global worldwide community is better integrated and more connected than it has ever been before. Globalisation then can probably cause less cultural diversity. Global consumer culture is transcending societal culture driven by global media visible through product categories, brands or consumption activities (Alden et al., 1999; Cleveland and Bartsch, 2018). On the other hand, despite a converging world and forceful efforts toward further integration, cross-cultural differences among countries will remain and will probably not disappear. Cultural patterns, inherited values and attitudes have deep roots in history and are very strong and stable. Mooij (2019) notes that people are not standardized and a global consumer does not exist.

The main objective of this paper is to investigate whether consumption functions vary among countries of European Union despite the globalisation penetrates the economic and social fields. The consumption function-related similarities and differences are interpreted in the context of national culture. A better comprehension of the consumption dynamics may be a valid guide for policymakers.

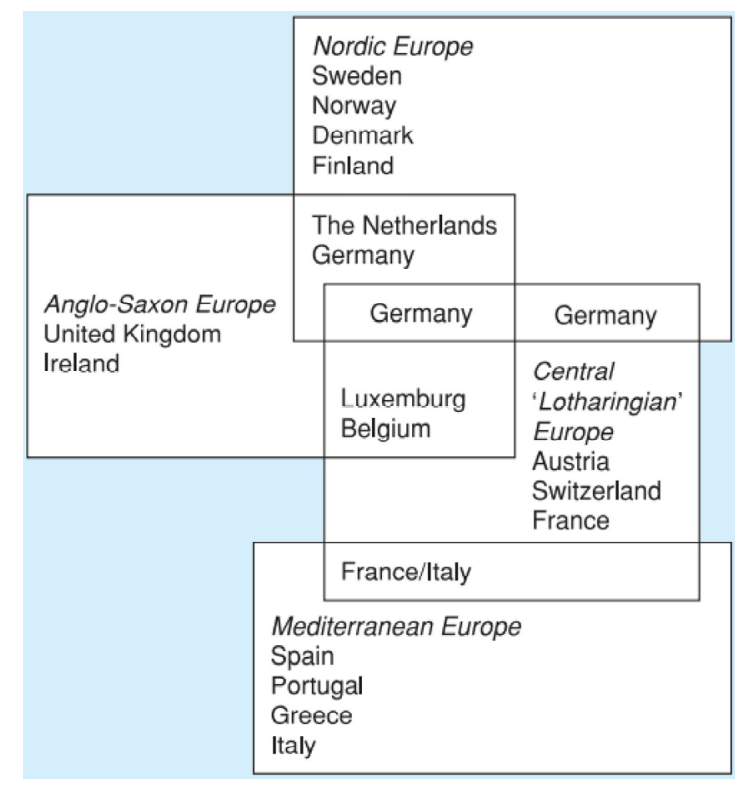

1: Cultural Affinity Zones

Usunier and Lee (2013)

\section{MATERIALS AND METHODS}

This empirical study is based on a panel data analysis using European Union countries (fundamental data for Malta are not available but the United Kingdom is integrated) data covering the period from the first quarter of 1995 until the final quarter of 2017. The data source for the time series of consumption expenditures and disposable income as well as gross domestic product is Eurostat (C2019). The country scores on the six dimensions of national culture are obtained from the country comparison created by Professor Geert Hofstede and are available on his website (Hofstede Insights, (C2019).

Only an annual frequency of disposable income data is available. The annual frequency of disposable income is divided into a quarterly frequency by external quarterly time series of real gross domestic product that is a relevant and economically related variable. A prerequisite for a consistent disaggregation of annual figures to quarterly figures is that the sum of quarterly values of real GDP per year have to be equal to the annual value of real GDP. The correlation coefficient between annual time series of GDP and annual time series of disposable income achieves a value of at least 0.9 in every country. Disposable income and GDP are without doubt economically related variables. The quarterly values of GDP are aggregated into an annual frequency and then the proportion of each quarter to annual value is calculated. Based on these proportional shares, the annual time series of disposable income is separated into a quarterly time series.

Economic variables (disposable income and consumption expenditures) are measured in the Euro currency as per capita aggregates. The TRAMO/SEATS procedure is applied to seasonally 
adjust these time series and a GDP implicit deflator is used to acquire the real terms of employed variables, the base year being 2010 .

For every country a dynamic regression model is applied to capture the characteristic of individual consumption function of every European Union country. Consumption is a function of current and lagged disposable income, which can be expressed by a dynamic regression model in the form:

$C_{t}=\beta_{0}+\beta_{1} C_{(t-1)}+\beta_{2} Y d_{t}+\varepsilon_{t}$.

The estimated parameters $\beta_{0}, \beta_{1}$ and $\beta_{2}$ are the input data for the cluster analysis. The standardized Euclidean distance among values of coefficients is calculated and for the evaluation of cluster similarity Ward's method is applied. According to dendrogram thereby obtained, the homogenous groups of European countries with similar consumption development are chosen. This operation helps to assign the typical cultural features to separated groups of countries with a similar consumption dynamics to uncover the consumption functionrelated similarities and differences in the context of national culture.

By using macro data involving 27 European countries over 23 years (92 quarters), panel data models are created. Consumption is modelled as a function of lagged consumption and disposable income.

$C_{i t}=\alpha_{i}+\beta_{1} C_{i(t-1)}+\beta_{2} Y d_{i t}+\varepsilon_{i t}$.

These Autoregressive distributed lag models are also estimated in the form of lagged consumption and various lags of disposable income. The regressions testing the predictive power of disposable income are inspired by Hall (1978).

$C_{i t}=\alpha_{i}+\beta_{1} C_{i(t-1)}+\beta_{2} Y d_{i t}+\beta_{3} Y d_{i(t-1)}+\ldots+\beta_{k} Y d_{i(t-p)}+\varepsilon_{i t}$. (3)

Panel data models are created for the group of all countries in this sample as well as for clusters of European countries obtained from the cluster analysis.

Testing for unit roots in the panel data is done using the Im, Pesaran and Shin test. The null hypothesis is that each series in the panel contains a unit root. The relationship among non-stationary time series is associated with the possible problem of spurious regression; this is why the cointegration test is also performed.

Correlation analysis is used to uncover the relationship between consumption expenditures and the cultural dimensions of European countries. When assigning the typical cultural features to single clusters of countries with a similar consumption dynamics, the attention is paid mainly to those cultural dimensions which are significantly correlated with consumption expenditures and disposable income.
The t-test is applied to demonstrate if the correlation coefficient is significantly different from zero. The significance level is 0.05. There is the fundamental presumption that the data are sampled randomly and normally distributed.

Scores on a cultural dimension illustrate a country's attitude towards a range of values and serve as a comparison of societies, put simply nations, which are the most relevant units to measure these disparities. Values vary on a scale from zero to one hundred. The number of concrete dimensions portrays an average value for each country and cannot present the belief of individuals. These six dimensions of national culture advise on the predictions of people's behaviour in certain situations.

Calculations are performed in the MATLAB R2018b computational system and Gretl, a significance level of 0.05 was maintained.

\section{RESULTS}

\section{Panel Data Analysis for the Whole Sample}

Panel data model is created for 27 European countries in this sample. Panel $\operatorname{ARDL}(1,1)$ is the most suitable form, only current and one lagged income help to explain consumption, further lags are not significant. Residuals are stationary and not autocorrelated.

$\hat{C}_{i t}=33.071+0.959 C_{i(t-1)}+0.585 Y d_{i t}-0.556 Y d_{i(t-1)}$.

Aggregate consumption seems to be relative stable over time. Coefficient reaches almost unity value and the effect of the current disposable income together with the lagged disposable income is moderately positive. Current consumption is predicted not only by the first lagged value of consumption but also by current and lagged disposable income. Lagged income has considerable predictable power beyond that of lagged consumption that is why the Permanent Income (Life-cycle) Hypothesis is discredited. Consumption appears to follow the excess sensitivity alternative hypothesis.

\section{Cluster Analysis}

For each of the 27 countries of the European Union (except Malta but including United Kingdom), dynamic regression models for consumption have been estimated.

Values of the estimated coefficients $a_{0}, \beta_{0}, \beta_{1}$ (equation number 2) were standardised and inserted into the cluster analysis and then the homogenous groups of European countries with a similar tendency of consumption development were obtained.

Fig. 2 displays a dendrogram where a set of countries actually disintegrates into classes, i.e. countries tend to group into natural clusters. 


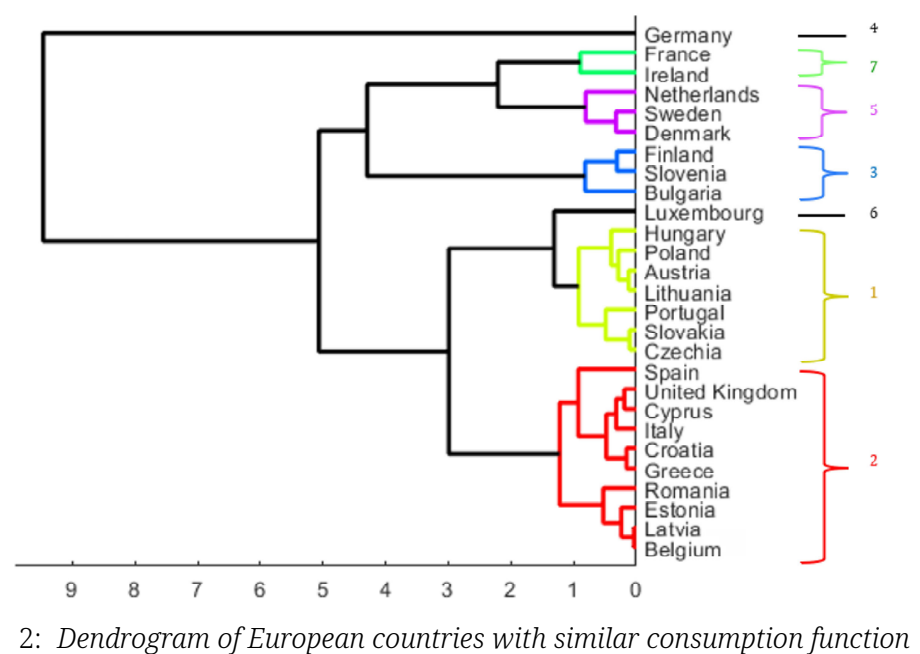

The dendrogram displays the big difference between Germany and the other countries. The consumption function of Germany shows a different character because current disposable income has considerable power beyond that of lagged consumption. Consumers from Germany are excessively evidently sensitive to current disposable income and do not distribute past income in an optimal manner.

There are then two groups of European countries - the first group more like the North and West Europe countries and a second group consisting mainly of South and Central Europe countries. The V4 countries (Czech Republic, Hungary, Poland and Slovakia), Austria, Lithuania and Portugal tend to be clustered together (pale green cluster). This cluster is quite close to the red one which is formed mainly of southern European countries. There are some exceptions and irregularities between localisations of European countries and created clusters - for example the cluster consisting of Finland, Slovenia and Bulgaria. Comparison of the result of clustering to cultural affinity zones created by Usunier and Lee (2013) displayed in Fig. 1 leads to some common results as well as some inconsistencies. Fig. 2 validates that the clustering did indeed group countries by the character of consumption function in terms of cultural affinity, too.

Panel data models are created also for clusters of European countries received from the cluster analysis. Clusters of European countries are portrayed in the context of Hofstede's cultural dimensions displayed on his website (Hofstede Insights, (c2019). Cluster number 1 (pale green cluster) consists of Czechia, Slovakia, Portugal, Lithuania, Austria, Poland and Hungary. These countries are more willingly centralised and hierarchically controlled and have a tendency to cynicism and pessimism (except Austria). People here are highly success-oriented but exhibit uncertainty avoidance. With the exception of Poland and Portugal, these countries show an ability to adapt to changing conditions. Cluster number 2 (red cluster) is formed by Belgium, Latvia, Estonia, Romania, Greece, Italy, Cyprus, the United Kingdom and Spain. Countries of this cluster are quite miscellaneous in the cultural context. They tend to prefer equality and a decentralisation of decision-making. Rituals, family network and mores are important social aspects, mainly for southern countries. These countries do not feel comfortable in ambiguous situations. Cluster number 3 (dark blue) is represented by Finland, Slovenia and Bulgaria, where people accept a hierarchical order but value free time, solidarity and quality in their working lives. Slovenia and Bulgaria are collectivistic societies.

Germany, as a solitaire with different character of consumption function, displays as a single cluster. Germany is among the lower power distant countries. Performance is highly valued and driven by competition, achievement and success. People here have a strong propensity to invest. Luxembourg - as cluster number 6 - shows a similar situation. The cultural background in Luxembourg is much like that in Germany. Luxembourg is however not so masculine but stands somewhere in between - at work the best win but in social matters people have a great sense of community. This society is more pragmatic than normative and has a tendency towards optimism. Cluster number 5 consists of the Netherlands, Sweden and Denmark. Countries of this cluster are the most cultural consistent. Power is decentralized, this individualistic society believes in independency and equal rights. Dominant values in this society are caring for others and the quality of life. They have a tendency towards optimism, enjoying life and spending money as they wish. Members of this cluster do not feel threatened by ambiguous or unpredictable situations and seek new and innovative products. Ireland and France, as individualistic countries, constitute a cluster number 7 (dark green). They seem to be similar in terms of consumption function, but they are 
different in terms of culture. Irish people believe that the inequalities of power distribution should be minimalised, people should be creative but exhibit great respect for traditions. The cultural environment is different in France - there is a strong need for laws, rules and regulations to structure life.

\section{Panel Data Analysis for the Formed Clusters}

A lagged disposable income as well as current disposable income has predictive value on current consumption expenditures in every cluster of European countries (Tab. I).

Estimations of clusters 1 and 5 are quite similar. Coefficient $\beta_{1}$ is getting near to unity value. A negative parameter of the first lag of disposable income is lightly outweighed by the positive coefficient of current disposable income. Estimations of clusters 2 are lower but the positive effect of disposable income is related.

The consumption functions of cluster 3 and 4 are related. The positive effect of the current disposable income combined with the lagged disposable income is higher.

Luxembourg's consumption function (cluster 6) is the only one with small but negative effect of disposable income because of higher negative coefficient of the lag than positive coefficient of the current income. This estimation does not indicate a negative relationship between disposable income and consumption. This situation has occurred because of the concrete value of the estimated parameters - the value of $\beta_{1}$ is one, that is why a negative effect of disposable income simply means that differences of consumption are negative. Indeed, Luxembourg's consumption is experiencing a decline, so changes between current and lagged consumption are negative.

France and Ireland (cluster 7) stand somewhere in between - on the one hand, the estimation of $\beta_{1}$ is lower and on the other hand, estimations of $\beta_{2}$ and $\beta_{3}$ are higher but the effect of disposable income is moderately positive.

Hendry (1995) created a list of distinct types and possible economic interpretations of the ARDL $(1,1)$ model. Because of the fact that coefficient $\beta_{1}$ is in

I: Panel data model coefficient estimations for each cluster: $C_{i t}=\alpha_{i}+\beta_{1} C_{i(t-1)}+\beta_{2} Y d_{i t}+\beta_{3} Y d_{i(t-1)}+\varepsilon_{i t}$

\begin{tabular}{ccccc}
\hline Cluster & $\alpha_{i}$ & $\beta_{1}$ & $\beta_{2}$ & $\beta_{3}$ \\
\hline 1 & -1.428 & 0.959 & 0.555 & -0.515 \\
2 & 28.119 & 0.955 & 0.444 & -0.410 \\
3 & 15.179 & 0.811 & 0.753 & -0.585 \\
4 & -25.753 & 0.870 & 0.846 & -0.730 \\
5 & 131.255 & 0.944 & 0.590 & -0.564 \\
6 & 80.937 & 1.033 & 0.390 & -0.427 \\
7 & 87.294 & 0.933 & 0.835 & -0.794 \\
\hline
\end{tabular}

every case nearly one and $\beta_{2}$ reaches almost the same value as $\beta_{3}$ but with the opposite sign, the "differenced data" type (growth rate model) of Hendry's models is used for interpretations.

The growth rate model $\Delta C_{i t}=a_{i}+\beta_{1} \Delta Y d_{i t}+\varepsilon_{i t}$ has been obtained from equation (4) by setting restriction $\beta_{1}=1$ and $\beta_{2}=-\beta_{3}$ in the $\operatorname{ARDL}(1,1)$ model. Using 27 European countries data the following model has been estimated.

$\Delta \hat{C}_{i t}=4.391+0.584 \Delta \mathrm{Yd}_{i t}$.

This model confirms the above-mentioned conclusions. The Permanent Income Hypothesis cannot be confirmed. A situation like this was explained by Campbell and Mankiw's (1990) statement that there are two groups of consumers - the first group consumes their current income (proportion of this group is represented by $\beta_{1}$ ) and the second consumes their permanent income (proportion of this group is represented by the remaining $\left.\left(1-\beta_{1}\right)\right)$. The error term symbolizes an unpredictable innovation to permanent income. An estimation of $\beta_{1}$ with value 0.584 rejects the Permanent Income Hypothesis which assumes that $\beta_{1}=0$. This implies that changes in consumption are predictable.

II: Growth rate panel data model coefficient estimations for each cluster: $\Delta C_{i t}=\alpha_{i}+\beta_{1} \Delta Y d_{i t}+\varepsilon_{i t}$

\begin{tabular}{ccc}
\hline Cluster & $\alpha_{i}$ & $\beta_{1}$ \\
\hline 1 & 5.053 & 0.554 \\
2 & 6.146 & 0.449 \\
3 & 3.109 & 0.753 \\
4 & 0.710 & 0.843 \\
5 & 2.792 & 0.595 \\
6 & -2.561 & 0.404 \\
7 & 0.824 & 0.838 \\
\hline
\end{tabular}

From the estimation of coefficient $\beta_{1}$ (Tab. II) it is evident that countries belonging to clusters 3, 4 and 7 have a higher share of current-income consumers. In countries allied to cluster 3 currentincome consumers receive $75 \%$ of total income and in countries from clusters 4 and 7 they receive as much as $84 \%$ of total income. Dynamic regression models in the form (1) for every single country of these notified clusters have shown that they have higher marginal propensity to consume than other countries.

Estimations of coefficient $\beta_{1}$ (Tab. II) for groups 2 and 6 reveal that they have a markedly lower fraction of income going to rule-of-thumb consumers.

For clusters 1 and 5 , the estimate of the population that consumes its current income is about 0.55 and 0.60 . 
III: Correlation analysis between consumption and disposable income and cultural dimensions

\begin{tabular}{lccccccc}
\hline & PDI & IDV & MAS & UAI & LTO & IVR \\
\hline \multirow{2}{*}{ Consumption } & -0.591 & 0.477 & -0.006 & -0.400 & -0.192 & 0.831 \\
\hline \multirow{2}{*}{ Disposable income } & $(0.002)$ & $(0.014)$ & $(0.976)$ & $(0.043)$ & $(0.347)$ & $(<0.001)$ \\
& -0.551 & 0.447 & 0.035 & -0.318 & -0.129 & 0.783 \\
\hline
\end{tabular}

Estimates of $\beta_{1}$ are always significant which means that forecastable changes in income should lead to predictable changes in consumption and the Permanent Income Hypothesis does not fit these data from European countries.

Models have been estimated with a view to avoid autocorrelation of the model's residuals. The Im, Pesaran and Shin panel unit root test was performed. For all the created models a lot of different panel data for consumption and disposable income was used and in some cases the panel unit root tests do not reject the null hypothesis of nonstationary panel data. Because of concerns over spurious regression, residuals from every model are tested using the Im, Pesaran and Shin panel unit root test. The threat of spurious regression has not been confirmed in any case.

\section{Correlation Analysis}

Findings of the correlation analysis are in Tab. III. Numbers in the table report the value of the correlation coefficient: in the first row, there are calculations of the strength of the relationship between the consumption expenditures (mean values over selected time) and the cultural dimensions of European countries and in the second row, there are the correlation coefficients of disposable income (mean values over selected time) and the cultural dimensions of European countries. In parentheses are the p-values for the null hypothesis that there is no relationship between selected variables.

There is a negative relationship between consumption expenditures and the power distance dimension (as well as between disposable income and the power distance dimension). Consumption expenditures are higher in countries where power is more equally distributed - like Denmark or Ireland. A positive correlation is significant between consumption expenditures and the individualism-collectivism dimension (as well as between disposable income and the individualismcollectivism dimension) and between consumption expenditures and the indulgence-restraint dimension (as well as between disposable income and the indulgence-restraint dimension). An individualistic culture, where individuals are expected to take care of themselves, is linked to rather higher consumption and income. As anticipated, a higher consumption expenditure is natural for a more hedonistic society. There is also a weaker positive correlation between consumption expenditure and the uncertainty avoidance dimension (a relationship between the uncertainty avoidance dimension and disposable income is not confirmed)

There is no relationship found between the masculinity-femininity dimension and consumption (and disposable income) likewise between the long term-short term orientation and consumption (and disposable income). Rejected correlations are accentuated in red in Tab. III.

\section{DISCUSSION}

A consumption function in the form of a dynamic regression has been formed for every European country. These estimated parameters have been applied to the cluster analysis and clusters describing groups of countries with similar character of consumption function have been created. These constructed clusters correspond to a certain extent to the cultural affinity zones.

Panel data models for the whole sample of European countries as well as for every created cluster show a positive correlation between the change in consumption and the lagged change in income. This conclusion is referred to as excess sensitivity of consumption and is consistent with the traditional work of Flavin (1981), Campbell and Deaton (1989), Campbell and Mankiw (1989), Broda and Parker (2014), Parker (2017) and Kueng (2018), who also rejected the Permanent Income Hypothesis/Random Walk Hypothesis. Flavin (1981) likewise Campbell and Mankiw (1989) believe that change in consumption is a weighted average of the change in current income and the innovation in permanent income.

The presence of borrowing constraints is a standard answer to the excess sensitivity phenomenon (Zeldes, 1989; Deaton, 1992; Carroll, 1997; Gourinchas and Parker, 2002; Kaplan and Violante, 2010, 2014; Jappelli and Pistaferri, 2011; Einian and Nili, 2020). This paper shows that the response to predictable income change is higher in the wealthier countries, or more precisely, there is a higher share of people consuming their current income. Credit constraints may not be the best explanation why consumption in relative economically flourishing countries reacts to expected income changes. Wealthier countries have probably a lower share of people facing liquidity constraints but the MPC out of current income is higher. Countries like Germany, Finland, 
Luxembourg and Ireland allocate higher excess sensitivity of consumption to current income. The departure from the Permanent Income-Life Cycle Hypothesis means non-optimal distributed lag behaviour which is associated with the loss in utility (Hall, 1978). This situation cannot then be rationalized by liquidity constraints but only by the lower loss from the non-optimally distributed past income when making consumption decisions (Kueng, 2018 and Lian, 2019). On the one hand, one possible reason is a trivial utility drop of the deviation from the optimality in these countries and on the other hand, cultural background with similar attitudes may be a reason. This individualistic culture with low score on Power Distance and tendency to optimism and less controlled behaviour might feel less guilty not smoothing the change in disposable income.

Other European countries tell a similar story, there is just a heterogeneity of a proportion of consumers consuming their current income. Countries mainly from the south of Europe have a lower fraction of rule-of-thumb consumers. This culture is considered fairly collectivistic and less tolerant of unexpected situations.
In the name of globalisation, there has been a prediction of the convergence of diverse cultures into a single world culture (Levitt, 1983). De Mooij (2003) argues that despite the convergence of media and national income, the variation of consumer behaviour across nations remains. Culture apparently plays a strong role in explaining this situation (de Mooij and Hofstede, 2011 and Terlutter et al., 2006). De Mooij (2003) has supported this idea by stating that the Hofstede model of national culture can interpret most of the diversity of consumption behaviour across countries. The persistence of cultural patterns implies that differences in culture should be recognized and taken into account in the debate over economic stimulus programmes.

In their papers, other authors (Schütte and Ciarlante, 1989; Suh and Kwon, 2002; Terlutter et al., 2006; de Mooij and Hofstede, 2011) have provided empirical support for the persistence of differences in consumers attitudes and perceptions in spite of extensive globalization. Studies say there is no such thing as a uniform Euro consumer, the cultural values developed by people within a nation survive.

\section{CONCLUSION}

Individual people are widely determined by the culture of society because consumers from the same cultural background share similar attitudes, preferences and cognition in contrast to other cultural backgrounds with different attitudes. The aspects of culture associated with the naturally formed clusters on the basis of the consumption function are important in national comparisons. Understanding the relationship between the consumption function (in sense of a relationship between consumption and disposable income) and culture can have macroeconomic policy implications as a consequence because it suggests that some consumption expenditures in some cultural groups of society are inclined to react more to changes in income.

Correlation analysis has revealed that there is a negative correlation between the power distance score and consumption (and disposable income) and a positive relationship between individualism and consumption (and disposable income) and indulgence and consumption (and disposable income). Consequently, interpretations of the connection between culture and the consumption function are mainly focused on these dimensions.

This paper documents significant excess sensitivity of consumption to current income across the whole sample of European countries as well as in the particular cultural groups of these countries. Consumption expenditures respond to changes in disposable income.

Excess sensitivity seems to be different among particular panels. On the one hand, less excess sensitivity is observed in southern countries, where uncertain situations are unpleasant. These countries prefer a loose social framework and deliberate in groups, not as individuals. The effectiveness of financial stimulus programmes created by the government will not be so effective here. The reactions of consumption to predictable changes in disposable income are weak. Consumption expenditures in these countries are rather highly persistent which confirms the ineffectiveness of countercyclical policies. On the other hand, countries with good economic positions like Germany, Finland, Luxembourg and Ireland have stronger responses of consumption to current income. In other words, there is the highest share of current-income consumers. These countries can be characterized by an indulgent culture; therefore, people have a tendency not to control their needs, desires and impulses and they enjoy life. A major part of these countries considers inequalities in the nation or an organisation to be inefficient and prefer participative and informal communication. Countries of the Visegrad Four plus Austria, Lithuania and Portugal stand somewhere in between. They show excess sensitivity as well as all countries in the panel analysis. The culture of this group is a combination of both the previous ones, which copies Cultural Affinity Zones created by Usunier 
and Lee (2013). This group of countries is distinguished by a masculine and restraint culture. This society works hard to build its position and control its leisure time and desires side-by-side. The persistence of consumption expenditures in the Visegrad Four countries (plus Austria, Lithuania and Portugal) is very high as in southern countries. This evidence for high persistence in aggregate consumption reflects strong habit formation mechanisms.

In spite of the recent phenomenon of globalisation, this paper offers the assumption that aspects of the consumption function remain bound by culture.

Acknowledgements

Supported by grant No PEF_DP_2020030 of the Grant Agency IGA PEF MENDELU.

\section{REFERENCES}

ALDEN, D. L., STEENKAMP, J. and BATRA, R. 1999. Brand positioning through advertising in Asia, North America, and Europe: the role of global consumer culture. Journal of Marketing, 63(1): 75-87.

BRODA, C. and PARKER, J. A. 2014. The Economic Stimulus Payments of 2008 and the Aggregate Demand for Consumption. Journal of Monetary Economics, 68(S): 20-36.

CAMPBELL, J. Y. and DEATON, A. 1989. Why Is Consumption So Smooth? Review of Economic Studies, 56(3): 357-374.

CAMPBELL, J. Y. and MANKIW, N. G. 1989. Consumption, Income, and Interest Rates: Reinterpreting the Time Series Evidence. In: NBER Macroeconomics Annual. Volume 4. National Bureau of Economic Research, pp. 185-246.

CARROLL, C. D. 1997. Buffer-stock Saving and the Life Cycle/Permanent Income Hypothesis. Quarterly journal of economics, 112(1): 1-55.

CLEVELAND, M. and BARTSCH, F. 2019. Global consumer culture: epistemology and ontology. International Marketing Review, 36(4): 556-580.

DE MOOIJ, M. 2003. Convergence and divergence in consumer behavior: Implications for global advertising. International Journal of Advertising, 22(2): 183-202.

DE MOOIJ, M. 2019. Fairy tales of global consumer culture in a polarizing world. International Marketing Review, 36(4): 581-586.

DE MOOIJ, M. and HOFSTEDE, G. 2011. Cross-Cultural Consumer Behavior: A Review of Research Findings. International Journal of Advertising, 23(3-4): 181-192.

DEATON, A. S. 1987. Life-Cycle Models of Consumption: Is the Evidence Consistent with the Theory? In: Advances in Econometrics. Fifth World Congress. Vol. II. Cambridge and New York: Cambridge University Press, pp. 121-148.

DEATON, A. S. 1992. Understanding Consumption. $1^{\text {st }}$ Edition. New York: Oxford University Press.

EINIAN, M. and NILI, M. 2020. Excess sensitivity and borrowing constraints: Evidence from Iranian households. Econ. Transit. Institut. Change, 28(1): 137-160.

EUROSTAT. 2019. GDP and main components (output, expenditure and income). Eurostat. [Online]. Available at: http://appsso.eurostat.ec.europa.eu/nui/show.do?dataset=nama_10_gdp\&lang=en [Accessed: 2019, July 14].

EUROSTAT. 2019. GDP and main components (output, expenditure and income).Eurostat. [Online]. Available at: http://appsso.eurostat.ec.europa.eu/nui/show.do?dataset=namq_10_gdp\&lang=en [Accessed: 2019, July 13].

EUROSTAT. 2019. Final consumption aggregates. Eurostat. [Online]. Available at: http://appsso. eurostat.ec.europa.eu/nui/show.do?dataset=namq_10_fcs\&lang=en [Accessed: 2019, July 13].

EUROSTAT. 2019. Population on 1 January by age and sex. Eurostat. [Online]. Available at: http:// appsso.eurostat.ec.europa.eu/nui/show.do?dataset=demo_pjan\&lang=en [Accessed: 2019, July 14].

FLAVIN, M. 1981. The Adjustment of Consumption to Changing Expectations about Future Income. Journal of Political Economy, 89(5): 974-1009.

FRIEDMAN, M. 1957. A Theory of the Consumption Function. $1^{\text {st }}$ Edition. Princeton: Princeton University Press.

GOURINCHAS, P.-O. and PARKER, J. A. 2002. Consumption over the Life Cycle. Econometrica, 70(1): 47-89.

HALL, R. E. 1978. Stochastic Implications of the Life Cycle-Permanent Income Hypothesis: Theory and Evidence. Journal of Political Economy, 86(6): 971-987.

HENDRY, D. 1995. Dynamic Econometrics. Oxford: Oxford University Press.

HOFSTEDE, G. 2019. Country Comparison. Hofstede Insights. [Online]. Available at: https://www. hofstede-insights.com/country-comparison/ [Accessed: 2019, September 05]. 
HOFSTEDE, G. 2001. Culture's Consequences: Comparing Values, Behaviors, Institutions, and Organizations Across Nations. $2^{\text {nd }}$ Edition. Thousand Oaks, CA: Sage.

HOFSTEDE, G. 2011. Dimensionalizing Cultures: The Hofstede Model in Context. Online Readings in Psychology and Culture, 2(1): 8.

HOFSTEDE, G., HOFSTEDE, G. J. and MINKOV, M. 2010. Cultures and Organizations: Software of the Mind. $3^{\text {rd }}$ Edition. New York: McGraw-Hill Education.

INKELES, A. and LEVINSON D. J. 1969. National character: The study of modal personality and sociocultural systems. The Handbook of Social Psychology, 4: 418-506.

JAPPELLI, T. and PISTAFERRI, L. 2011. The Consumption Response to Income Changes. Annual Review of Economics, 2(1): 479-506.

KALE, S. 1995. Grouping Euroconsumers: A Culture-Based Clustering Approach. Journal of International Marketing, 3(3): 35-48.

KAPLAN, G. and VIOLANTE, G. L. 2010. How much Consumption Insurance beyond Self-insurance? American Economic Journal: Macroeconomics, 2(4): 53-87.

KAPLAN, G. and VIOLANTE, G. L. 2014. A Model of the Consumption Response to Fiscal Stimulus Payments. Econometrica, 82(4): 1199-1239.

KEYNES, J. M. 1936. The general theory of employment, interest, and money. Palgrave Macmillan.

KLUCKHOHN, C. K. 1951. Values and value orientations in the theory of action. In: PARSONS, T. and SHILS, E. A. (Eds.). Toward a general theory of action. Cambridge, MA: Harvard University Press.

KUENG, L. 2018. Excess Sensitivity of High-Income Consumers. The Quarterly Journal of Economics, 133(4): 1693-1751.

LEVITT, T. 1983. The globalization of markets. Harvard Business Review, 83(3): 92-102.

LIAN, C. 2019. Consumption with Imperfect Perception of Wealth. Working paper. Economics MIT.

MODIGLIANI, F. and BRUMBERG, R. 1954. Utility analysis and the consumption function: an interpretation of cross-section data. In: KURIHARA, K. K. (Ed.). Post-Keynesians Economics. New Brunswick: Rutgers University Press, pp. 388-436.

PARKER, J. 2017. Why Don't Households Smooth Consumption? Evidence from a 25 Million Dollar Experiment. NBER Working Paper, No. 21369. NBER.

SCHÜTTE, H. and CIARLANTE, D. 1998. Consumer Behaviour in Asia. London: Palgrave Macmillan UK. SUH, T. and KWON, I. 2002. Globalization and reluctant buyers. International Marketing Review, 19(6): 663-680.

TERLUTTER, R., DIEHL, S. and MUELLER, B. 2006. The GLOBE study - applicability of a new typology of cultural dimensions for cross-cultural marketing and advertising research. In. International Advertising and Communication. Wiesbaden: Deutscher Universitäts-Verlag, pp. 421-438.

USUNIER, J.-C. and LEE, J. A. 2013. Marketing across cultures. $6^{\text {th }}$ Edition. London, UK: Pearson. USUNIER, J-C. 2000. Marketing Across Cultures. $3^{\text {rd }}$ Edition. London: Prentice Hall.

ZELDES, S. 1989. Consumption and Liquidity Constraints: An Empirical Investigation. Journal of Political Economy, 97(2): 305-346.

Contact information

Terézia Vančová: terezia.vancova@mendelu.cz

Luboš Střelec: lubos.strelec@mendelu.cz 